University of Nebraska - Lincoln

DigitalCommons@University of Nebraska - Lincoln

USDA National Wildlife Research Center - Staff Publications
U.S. Department of Agriculture: Animal and Plant Health Inspection Service

2014

\title{
Evaluating the Effect of Short-Term Capture and Handling on Fecal Glucocorticoid Metabolite Levels in Mourning Doves
}

\author{
D. S. Jachowski \\ Department of Fisheries and Wildlife Sciences, djachowski@gmail.com
}

T. W. Wong

Department of Fisheries and Wildlife Sciences

B. E. Washburn

Department of Fisheries and Wildlife Sciences, brian.e.washburn@aphis.usda.gov

J. H. Schulz

Department of Fisheries and Wildlife Sciences

J. J. Millspaugh

Department of Fisheries and Wildlife Sciences, joshua.millspaugh@umontana.edu

Follow this and additional works at: https://digitalcommons.unl.edu/icwdm_usdanwrc

Part of the Life Sciences Commons

Jachowski, D. S.; Wong, T. W.; Washburn, B. E.; Schulz, J. H.; and Millspaugh, J. J., "Evaluating the Effect of Short-Term Capture and Handling on Fecal Glucocorticoid Metabolite Levels in Mourning Doves" (2014). USDA National Wildlife Research Center - Staff Publications. 1508.

https://digitalcommons.unl.edu/icwdm_usdanwrc/1508

This Article is brought to you for free and open access by the U.S. Department of Agriculture: Animal and Plant Health Inspection Service at DigitalCommons@University of Nebraska - Lincoln. It has been accepted for inclusion in USDA National Wildlife Research Center - Staff Publications by an authorized administrator of DigitalCommons@University of Nebraska - Lincoln. 


\title{
TECHNICAL NOTE
}

\section{Evaluating the Effect of Short-Term Capture and Handling on Fecal Glucocorticoid Metabolite Levels in Mourning Doves}

\author{
D.S. Jachowski ${ }^{1,2, *}$, T.W. Mong ${ }^{1}$, B.E. Washburn ${ }^{1,3}$, J.H. Schulz ${ }^{1,4}$ \& J.J. Millspaugh ${ }^{1}$
}

1 Department of Fisheries and Wildlife Sciences, Univ. of Missouri, 302 ABNR Building, Columbia, MO 65211, USA.

2 Department of Fish and Wildlife Conservation, Virginia Tech, 106 Cheatham Hall, Blacksburg, VA 24061, USA.

3 USDA, Wildlife Services, National Wildlife Research Center, 6100 Columbus Avenue, Sandusky, OH 44870, USA.

4 Missouri Department of Conservation, Conservation Research Center, 1110 South College Avenue, Columbia, MO 65201, USA.

* Corresponding author e-mail: djachowski@gmail.com.

\begin{tabular}{ll}
\hline Keywords & Abstract \\
Stress; & The measurement of stress hormones (i.e., glucocorticoids) has greatly \\
Physiology; & advanced animal conservation. Fecal glucocorticoid metabolite assays \\
Handling; & are valuable because they are noninvasive, but their ability to detect \\
Captivity; & responses to short-term ( $<30 \mathrm{~min})$ stressors in a way similar to blood \\
Mourning dove. & serum assays is comparatively less well understood. We evaluated \\
whether fecal glucocorticoid metabolites (FGMs) increased in captive \\
wild mourning doves (Zenaida macroura) exposed to either a brief \\
( $<2$ min) capture, handling and release (CHR) or capture stress protocol \\
(CSP; i.e., capture, hold for 30 min, release) treatment. Previous studies \\
have shown that mourning doves exhibit elevated FGMs within 2-3 hrs of \\
experimental challenges. Therefore, we attempted to collect feces every \\
hour for 24 pre-treatment and 36 host-treatment. We did not detect \\
a consistent increase in FGMs in response to CHR or CSP treatments. \\
Though additional research is needed, FGM levels were lower the longer \\
birds were held in captivity and we did not observe sex-based or seasonal \\
differences in FGM responses. For mourning doves, and likely other \\
species, plasma corticosterone analysis is better suited to assess responses \\
to short-term stressors. Alternatively, FGMs are ideal for research focused \\
on longer-term patterns in physiological state because they are not sensitive \\
to exposure to temporary, acute stressors.
\end{tabular}

\section{Introduction}

Measurement of stress hormone production in wildlife has dramatically improved our understanding of their physiology, behavior, and conservation [1, 2, 3, 4]. For avian species, in particular, non-lethal means of assessing stress hormone concentrations 
through collection of blood samples has revolutionized our understanding of physiological mechanisms involved with migration [5, 6], social interactions [7], foraging behavior [8,9,10], reproductive timing [11], and parasitism [12]. Of particular interest to conservation managers, elevated glucocorticoid levels are associated with individual fitness or health that can, in turn, be used to assess broader population- or species-level responses to environmental change [2, 13, 14, 15].

Monitoring changes in fecal glucocorticoid metabolite (FGM) levels provides a noninvasive alternative to monitoring glucocorticoid concentration in blood plasma $[16,17,18,19]$. FGM analyses have been widely used, particularly in wild settings, because samples can be collected frequently and non-invasively from focal individuals $[20,21]$ and FGMs might provide a broader integrated measure of the stress response than blood glucocorticoid levels [22]. Moreover, studies using blood glucocorticoid sampling have found that capture and handling might compromise an accurate assessment of glucocorticoid levels [23, 24]. The ability of FGM assays to detect responses to short-term stressors in wild animals, often of interest in field studies, is less well understood. For example, when FGM techniques are combined with behavioral studies involving capture, handling, and restraint to collect biological data (e.g., attach leg bands or radio transmitters), it is important to determine whether or not fecal glucocorticoid analyses are capable of detecting associated short-term stress responses if and when they occur [25, 26].

In this study we investigated if FGM assays were able to detect exposure to short-term stressors by continuously sampling mourning doves (Zenaida macroura) in a captive setting. Mourning doves provide an ideal study subject because FGM assays have been validated, and elevations in FGMs are known to occur within 2-3 hrs following exposure to acute stressors such as experimental challenge with adrenocorticotrophin (ACTH) [27]. We built on this basic experimental understanding of FGM responses in mourning doves by conducting trials on captive wild doves exposed to two different stress regimes; a short-term $(<2 \mathrm{~min})$ stressor mimicking capture and banding, and a longer term $(<30 \mathrm{~min})$ stressor simulating the amount of time needed to capture, handle, and attach a radio transmitter to a bird.

\section{Methods}

We captured wild mourning doves near Columbia, Missouri (38 $54^{\prime} \mathrm{N}, 92^{\circ} 18^{\prime} \mathrm{W}$ ) using modified Kniffin traps [28] during December 2000 to June 2001. Upon capture, we banded each bird with an individually numbered metal leg band, and assigned age and gender based on plumage characteristics [29, 30]. We transported mourning doves to the T.S. Baskett Wildlife Research and Education Area, located $15 \mathrm{~km}$ south of Columbia, Missouri $\left(38^{\circ} 45^{\prime} \mathrm{N}, 92^{\circ} 11^{\prime} \mathrm{W}\right)$. During captivity, doves were kept individually in outdoor $1.8 \mathrm{~m} \times 1.8 \mathrm{~m} \times 1.8 \mathrm{~m}$ wooden framed pens raised $0.6 \mathrm{~m}$ above ground [31]. A wild-bird seed mixture (sorghum grains, wheat, crimped corn, oats, and sunflower seed) and water were provided ad libitum.

Due to logistical constraints and our need to continuously sample dove glucocorticoid metabolites to address our study objectives, our sampling was necessarily focused on intensively monitoring a small number of individuals $(n=6)$. We administered 3 different treatment protocols over the course of 18 months (Table 1). During the first 
experiment in winter (January) 2001, we administered a capture stress protocol (CSP) treatment [1] to two doves that had been in captivity for 6 weeks (Table 1). These birds were captured at 1200 and immediately placed into a breathable cotton sack. We placed the birds in a sternal position in the sack for $30 \mathrm{~min}$, at which time we released them back into their respective pens (total disturbance time of $30 \mathrm{~min} 47 \mathrm{~s}+/-16 \mathrm{SE} \mathrm{s}$ ).

Table 1: Summary of experimental treatments used to evaluate short-term stress events in wild mourning doves held in captivity.

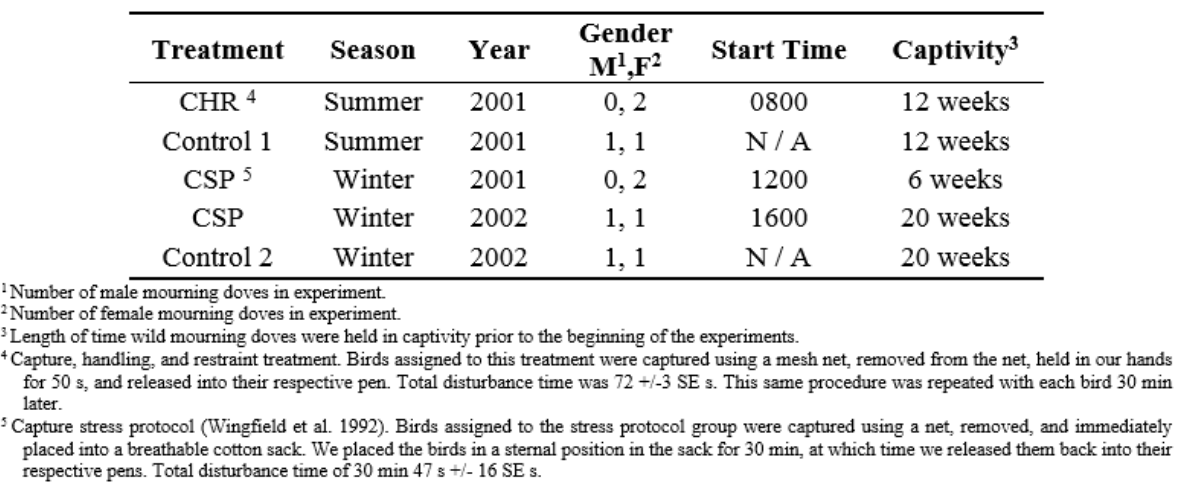

A second experiment was conducted in summer (July) 2001, when we administered brief $(<2 \mathrm{~min})$ capture, handling, and release (CHR) treatments to 2 doves and simultaneously monitored 2 additional doves that were not handled and where only droppings were collected (serving as a control). Individual birds were randomly assigned to treatments. We attempted to assign one male and one female to each treatment, but errors in assigning gender [30] precluded equal numbers of males and females in each treatment. Control birds were not captured, handled, or restrained. The 2 doves assigned to the CHR treatment group were captured using a mesh net (at 0800), removed from the net, held in our hands for $50 \mathrm{~s}$, and released into their respective pen (total disturbance time of $72+/-3 \mathrm{SE} s$ ). This same procedure was repeated with each bird $30 \mathrm{~min}$ later to extend the length of adrenocortical stimulation.

We conducted a third experiment in winter (February) 2002, when we again administered a CSP treatment to 2 doves (Table 1). We followed methods similar to winter 2001, with three key differences: (1) this group of doves had been in captivity for 20 weeks, (2) we administered treatment at 1600 (as opposed to 1200) to try to determine if response differed by time of day [e.g., 32, 33], and (3) we simultaneously sampled 2 control doves (Table 1).

We collected droppings (feces plus urine) from each individual bird every hour, when available, beginning $24 \mathrm{~h}$ pre-treatment and continuing for $36 \mathrm{~h}$ post-treatment (except for the winter 2001 experiments when sample collection continued until 30 $\mathrm{h}$ post-treatment). While feces and urine often contain differing FGM levels and thus sample-to-sample variation in feces:urine ratio could influence our ability to detect trends in FGMs [17], we were logistically unable to separate feces from urine for this study. Droppings were frozen at $-20^{\circ} \mathrm{C}$ within $10 \mathrm{~min}$ of collection. We placed frozen droppings into a lyophilizer (Freeze-dry Specialties, Inc., Osseo, MN, USA) for $24 \mathrm{~h}$. Once freeze-dried, we sifted samples through a stainless steel mesh to remove large 
particles; each sample was then thoroughly mixed. We extracted fecal glucocorticoid metabolites from feces using a modification of Schwarzenberger et al. [34]. We placed dried feces $(0.016$ to $0.120 \mathrm{~g})$ in a test tube with $2.0 \mathrm{~mL}$ of $90 \%$ methanol and vortexed the sample at high speed in a multi-tube vortexer for $30 \mathrm{~min}$. We centrifuged samples at $500 \mathrm{x} \mathrm{g}$ for $20 \mathrm{~min}$, saved the supernatant, and stored it at $-84^{\circ} \mathrm{C}$ until assayed.

We used ${ }^{125}$ corticosterone radioimmunoassay (RIA) kits (ICN \#07-120103, ICN Biomedicals, Solon, OH, USA) previously validated for use in mourning doves [27] to quantify glucocorticoid metabolite concentrations. Droppings were analyzed in 10 assays, with each assay including all the samples from an individual bird. We followed the ICN protocol for the I ${ }^{125}$ corticosterone RIA, except that we halved the volume of all reagents. Inter-assay variation for four assays was $5.3 \%$ and average intra-assay variation was $1.3 \%$.

We calculated summary statistics of mean, standard deviation and coefficient of variation for each individual dove prior to and following treatment. We also calculated baseline FGM levels for each individual during each experiment using methods outlined by Brown et al. [35] that involved an iterative process where we excluded FGM values that exceeded the mean plus $1.5 \mathrm{SD}$ and recalculated a mean value until no values exceeded the mean plus 1.5 SD. The final mean FGM value for each individual dove in each experiment was termed the baseline for that individual.

\section{Results}

We collected and assayed an average of 53.5 samples/bird $(\mathrm{SE}=2.33$, Range $=$ $47-60, n=10$ ) during this study (total of 535 droppings). Mourning doves defecated at a rate of $0.9 \mathrm{samples} / \mathrm{bird} /$ hour during our experiments $(\mathrm{SE}=0.04$, Range $=0.8-1$, $n=10)$.

We did not observe consistent short-term elevations in FGMs following exposure to acute CHR and CSP stressors. Baseline FGM values for individuals in both treatment and control groups were in a similar range of $25-32 \mathrm{ng} / \mathrm{g}$, and we observed no discernible trend in FGMs following our summer 2001 CHR treatment (Fig. 1). Further, the CHR treatment and control groups exhibited similar amounts of variability and similar FGM values over the course of the study (Table 2).

During the winter 2001 CSP treatment, pre-treatment (i.e., baseline) FGM levels were two times higher than FGM levels of all other birds during the pre-treatment period (Fig. 2). Post-treatment, in both doves we observed peaks in FGMs that were two times baseline FGMs in the first $6 \mathrm{hrs}$ after treatment and then again 23-29 hrs post-treatment (Fig. 2). However, between these peaks FGMs were not consistently elevated nor did variation in FGMs increase substantially compared to pre-treatment levels (Table 2).

In contrast to the winter $2001 \mathrm{CSP}$ treatment, we observed no discernible increase in FGMs following CSP treatment in winter 2002 (Fig. 3). The doves used in the winter 2002 CSP treatment had been maintained in captivity for 20 weeks and were treated at 1600 (cf. the winter 2001 CSP treatment in Table 1) and both treatment and control groups exhibited lower baseline FGMs in comparison to doves in the two previous experiments (Fig. 3). Post-treatment, we did not observe an increase in FGMs for 


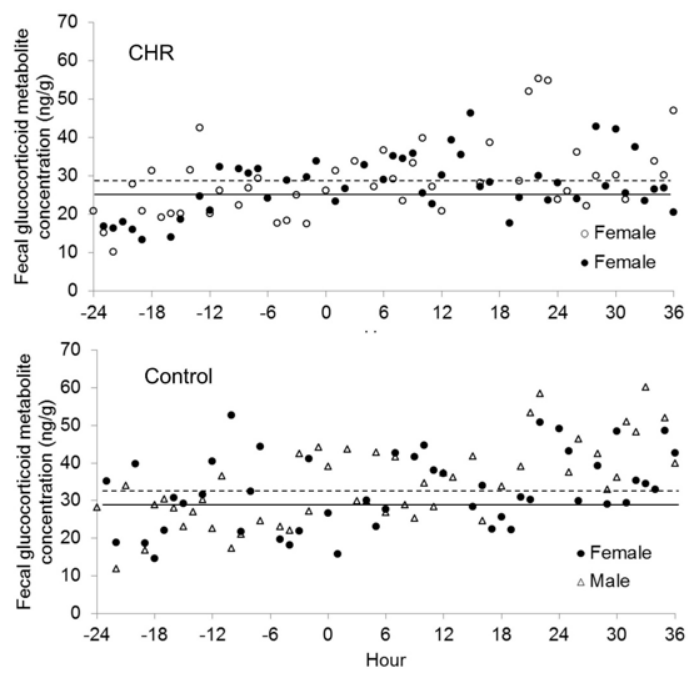

Figure 1: Fecal glucocorticoid concentrations (ng/g) of two mourning doves assigned to the capture, handling, and release (CHR) treatment group ( $n=2$ females) in summer 2001 over $60 \mathrm{~h}$ (top panel). Study began at 08:00 h. Time 0 represents the time when capture, handle and restraint (CHR) treatments were administered. No treatments were administered to the control group ( $n=1$ male, $n=1$ female) (lower panel). Lines represent baseline fecal glucocorticoid concentrations (ng/g) for each individual (dashed line corresponds with hollow points, solid line with solid points).

Table 2: Summary of experimental treatments used to evaluate short-term stress events in wild mourning doves held in captivity.

\begin{tabular}{lccccc}
\hline Treatment & $\begin{array}{c}\text { Gender } \\
\text { (M, F) }\end{array}$ & $\begin{array}{c}\text { Mean (SD) fecal glucocorticoid } \\
\text { metabolite concentration } \\
\text { Pre-treatment }\end{array}$ & \multicolumn{2}{c}{ Coefficient of Variation } \\
& Post-treatment & Pre-treatment & Post-treatment \\
\hline CHR & F & $23.3(7.0)$ & $33.2(9.7)$ & 0.3002 & 0.2925 \\
& F & $23.6(7.3)$ & $29.7(7.0)$ & 0.3086 & 0.2360 \\
Control 1 & M & $27.4(8.3)$ & $39.3(9.8)$ & 0.3042 & 0.2491 \\
& F & $29.5(10.6)$ & $34.7(9.2)$ & 0.3607 & 0.2642 \\
CSP & F & $44.4(14.0)$ & $50.6(21.3)$ & 0.3155 & 0.4202 \\
& F & $56.5(16.2)$ & $76.6(16.0)$ & 0.2872 & 0.2093 \\
CSP & M & $16.7(2.8)$ & $17.3(4.0)$ & 0.1694 & 0.2317 \\
& F & $24.4(5.8)$ & $29.6(7.9)$ & 0.2379 & 0.2689 \\
Control 2 & M & $10.1(2.1)$ & $12.8(2.8)$ & 0.2085 & 0.2177 \\
& F & $14.6(4.0)$ & $16.1(3.5)$ & 0.2762 & 0.2180 \\
\hline
\end{tabular}

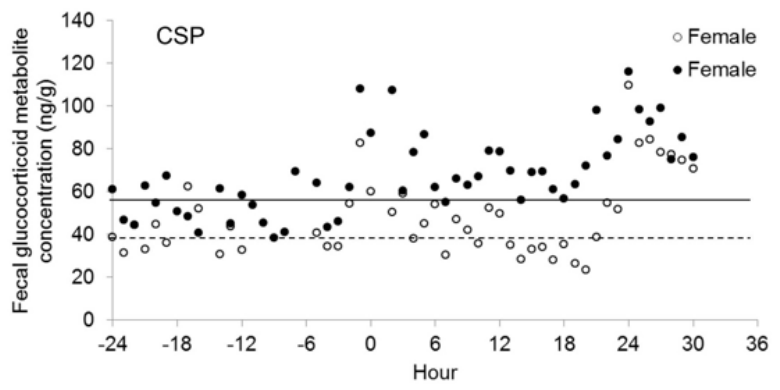

Figure 2: Fecal glucocorticoid concentrations (ng/g) of two mourning doves assigned to the stress protocol treatment group in winter $2001(n=2$ females) over $54 \mathrm{~h}$. Time 0 represents the time when capture stress protocol (CSP; Wingfield et al. 1992) treatments were administered. Study began at 12:00 h. Lines represent baseline fecal glucocorticoid concentrations (ng/g) for each individual (dashed line corresponds with hollow points, solid line with solid points). 

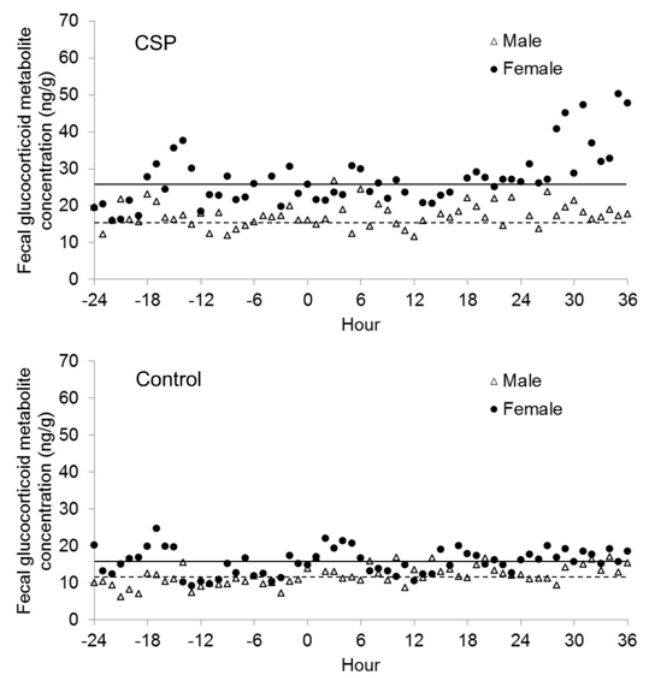

Figure 3: Fecal glucocorticoid concentrations (ng/g) of two mourning doves assigned to the capture stress protocol (CSP; Wingfield et al. 1992) treatment group ( $n=1$ male, $n=1$ female) in winter 2002. Time 0 represents the time when treatments were administered. Study began at 16:00 h. No treatments were administered to the control group ( $n=1$ male, $n=1$ female) (lower panel). Lines represent baseline fecal glucocorticoid concentrations (ng/g) for each individual (dashed line corresponds with hollow points, solid line with solid points).

the male dove, and only observed an increase in FGMs for the female dove after 24 hrs (Fig. 3). Across our entire study, this was the only evidence to suggest sexbased differences in FGM responses by mourning doves to our treatments. Finally, coefficient of variation values were similar pre- and post-treatment across both groups (Table 2).

\section{Discussion}

Although our study was restricted to a small number of individual birds, failure to observe consistent elevations in FGMs following CHR or CSP treatments suggests that, compared to blood, fecal sampling is not sensitive to elevations in glucocorticoid concentrations in response to short-term, acute stressors in mourning doves. Previous studies with captive mourning doves indicated that a significant increase in plasma corticosterone occurred in response to the CHR protocol used in this study $[36,37]$. Therefore, although plasma corticosterone levels were likely elevated in response to CHR during our study, no elevation was evident in the fecal glucocorticoid metabolite profiles. Because FGMs reflect adrenocortical activity over an extended time period [22], and any acute response is lost because it is integrated, we think that this resulted in a loss of resolution of the stress response in feces.

Stressor-specific differences associated with the duration of a stressor might have contributed to the lack of elevations in FGM following capture and handling. In contrast to our relatively short term $(<30 \mathrm{~min})$ handling stress protocols, elevations in FGMs have been observed following exposure to other types of stressors. For example, dickcissels (Spiza americana) that were captured and had radio-transmitter 
backpacks attached to them elicited a peak in FGMs for $3 \mathrm{hrs}$, between 9-12 hrs following transmitter attachment [25]. We did not observe a similar acute stress response in our study despite knowing that it only takes 2-3 hrs for glucocorticoids to be detected in feces in mourning doves following ACTH challenge [27]. The absence of short-term elevations in FGMs during this study suggests that stressors $\geqslant 30 \mathrm{~min}$ (e.g., a permanently attached transmitter) might result in an acute or longterm elevation in FGMs, but that activities associated with handling $<30$ min do not elevate FGMs in mourning doves. Therefore, our results provide some assurance for managers and researchers that individual doves will not demonstrate long-term physiological effects resulting from capture and marking lasting $<30 \mathrm{~min}$ as is frequently performed during national banding activities [38, 39, 40].

Captivity can influence endocrine functional responses in avian species [41] and significantly affect corticosterone levels [5, 42]. Following capture, handling and radio-transmitter attachment in wild dickcissels that were acclimated to captivity for at least 2 weeks, Seudkamp Wells et al. [25] observed elevations in FGMs in birds receiving transmitter attachments, but no response in control birds. Similarly, our findings support previous reports that detecting stress responses in FGMs is likely dependent on acclimation time. Evidence from our 2 winter CSP treatments suggest that length of time mourning doves were held in captivity was associated with decreased inter-sample variability and overall lower FGM levels. Further, decreased variability in FGMs over the course of our study suggests that by week 20, either physiological acclimatization had occurred (i.e., doves no longer considered captivity to be a stressor) or that chronic stress diminished the overall ability of the birds to mount a physiological stress response to stressors [43, 44, 45]. Therefore, similar to blood-based corticosterone assays, the effects of captivity on FGMs is an important, potentially confounding factor that should be accounted for when trying to extend findings from the laboratory to the field, and vice-versa [41, 42].

Further research is needed to differentiate the potential effect of time of day or season on mourning dove FGMs. Evidence from blood sampling of circulating corticosterone levels in avian species suggests that diel rhythms occur; baseline corticosterone levels are lowest mid-day and individuals that are most sensitive to stressors exhibit greatest increases in corticosterone levels early in the morning after waking $[32,33]$. In contrast, the limited evidence we observed for elevation in FGMs following treatment was during 1200 (Fig. 2) and not during the earlier 0800 treatment. Further, comparison of controls between experiments conducted at 0800 and 1600 (although during differing seasons) supports the overall trend in that mourning dove baseline FGMs were not lowest in the early morning hours after waking. In addition to fine-scale diel rhythms, seasonal trends in corticosterone and adrenal responsiveness have been observed in a diversity of avian species [46, 47, 48, 49, 50]. For example, Romero et al. [51] found that plasma corticosterone levels and responses to CSP differed by season in White-crowned Sparrows, and that levels and responsiveness were lowest during fall migration and in winter, and highest during active breeding in summer. Although we observed some of the highest FGM values for doves sampled during the winter 2001 period, doves sampled during winter 2002 that were exposed to a similar CSP treatment protocol exhibited the lowest observed FGM values over the course of the study (Fig. 3). Collectively, our findings suggest that time of day and seasonal differences on FGMs were inconsistent, and likely of 
secondary importance compared to other environmental factors, most notably time in captivity.

Although our results suggest that FGM analyses are not appropriate for detecting acute physiological responses to short-term stressors in mourning doves and likely other avian species, these methods apparently provide a better-integrated measure of adrenocortical responses in long-term field studies. The main utility of FGM monitoring techniques likely involves long-term studies where frequently repeated sample collection from focal individuals is required [27, 52]. Fecal glucocorticoid metabolite analyses might provide a better-integrated measure of adrenocortical responses because they are less sensitive to short-term stressors or disturbances (e.g., predator walking by captive bird colony) that could otherwise bias interpretation of assay results [22, 53]. Further, noninvasive FGM monitoring, used concurrently with the collection of other physiological (e.g., body condition) or demographic parameters (e.g., recruitment), might be effective for examining the effects of potential chronic stressors $[54,55]$. We encourage researchers to consider stressor-specific differences, ease of sampling, and the physiological question of interest (i.e. baseline conditions or response to short-term, acute stressors) when determining which sampling technique is most appropriate.

\section{Acknowledgments}

Financial and logistical support for this project was provided by the University of Missouri (MU) Department of Fisheries and Wildlife Sciences, a MU Life Science Mission Enhancement Postdoctoral Fellowship, a MU Research Board Grant, the Missouri Department of Conservation (Federal Aid in Wildlife Restoration Project W-13-R), and the 2001 Webless Migratory Game Bird Research Program (United State Fish and Wildlife Service and the United States Geological Survey - Biological Resources Division). Fecal glucocorticoid assays were conducted in the Wildlife Stress Physiology Laboratory in the Department of Fisheries and Wildlife Sciences at the University of Missouri-Columbia. We thank B. Crampton, S. Kistner, B. Hoenes, T. Bonnot, R. Woeck, and C. Rittenhouse for their assistance in pen construction and/or feces collection. This research was approved by the University of Missouri Animal Care and Use Committee (Protocol \#3581).

\section{References}

Five "key references", selected by the authors, are marked below (Three recommended (•) and two highly recommended $(\bullet \bullet)$ papers).

1. Wingfield, J.C., Vleck, C.M., \& Moore, M.C. 1992. Seasonal changes in the adrenocortical response to stress in birds of the Sonoran Desert. J Exp Zool 264:419-428. http://dx.doi.org/10.1002/jez.1402640407

2. Bonier, F., Moore, I.T., Martin, P.R., \& Robertson, R.J. 2009. The relationship between fitness and baseline glucocorticoids in a passerine bird. Gen Comp Endocr 163:208-213. http://dx.doi.org/10.1016/j.ygcen.2008.12.013

3. Ouyang, J.Q., Sharp, P.J., Dawson, A., Quetting, M., \& Hau, M. 2011. Hormone levels predict individual differences in reproductive success in a passerine bird. P Roy Soc B 278: 2537-2545. http://dx.doi.org/10.1098/rspb.2010.2490

4. Schoech, S.J., Rensel, M.A., \& Heiss, R.S. 2011. Short-and long-term effects of developmental corticosterone exposure on avian physiology, behavioral phenotype, cognition, and fitness: a 
review. Curr Zool 57:514-530.

5. Piersma, T., \& Ramenofsky, M. 1998. Long-term decreases of corticosterone in captive migrant shorebirds that maintain seasonal mass and moult cycles. J Avian Biol 29:97-104. http://dx.doi.org/10.2307/3677186

6. Piersma, T., Reneerkens, J., \& Ramenofsky, M. 2000. Baseline corticosterone peaks in shorebirds with maximal energy stores for migration: a general preparatory mechanism for rapid behavioral and metabolic transitions? Gen Comp Endocr 120:118-126.

http://dx.doi.org/10.1006/gcen.2000.7543

7. Carere, C., Groothuis, T.G.G., Möstl, E., Daan, S., \& Koolhaas, J.M. 2003. Fecal corticosteroids in a territorial bird selected for different personalities: daily rhythm and the response to social stress. Horm Behav 43:540-548.

http://dx.doi.org/10.1016/S0018-506X(03)00065-5

8. Pravosudov, V.V. 2003. Long-term moderate elevation of corticosterone facilitates avian foodcaching behaviour and enhances spatial memory. P Roy Soc B 270: 2599-2604.

http://dx.doi.org/10.1098/rspb.2003.2551

9. Lohmus, M., Sundström, L.F., \& Moore, F.R. 2006. Non-invasive corticosterone treatment changes foraging intensity in red-eyed vireos Vireo olivaceus. J Avian Biol 37: 523-526.

http://dx.doi.org/10.1111/j.0908-8857.2006.03733.x

10. Crossin, G.T., Trathan, P.N., Phillips, R.A., Gorman, K.B., Dawson, A., Sakamoto, K.Q. \& Williams, T.D. 2012. Corticosterone predicts foraging behavior and parental care in macaroni penguins. Am Nat 180:E31-E41.

http://dx.doi.org/10.1086/666001

11. Schoech, S .J., Rensel, M.A., Bridge, E.S., Boughton, R.K., \& Wilcoxen, T.E. 2009. Environment, glucocorticoids, and the timing of reproduction. Gen Comp Endocr 163:201-207. http://dx.doi.org/10.1016/j.ygcen.2008.09.009

12. Raouf, S.A., Smith, L.C., Brown, M.B., Wingfield, J.C., \& Brown, C.R. 2006. Glucocorticoid hormone levels increase with group size and parasite load in cliff swallows. Anim Behav 71:39-48. http://dx.doi.org/10.1016/j.anbehav.2005.03.027

13. Marra, P.P., \& Holberton, R.L. 1998. Corticosterone levels as indicators of habitat quality: effects of habitat segregation in a migratory bird during the non-breeding season. Oecologia 116:284-292.

http://dx.doi.org/10.1007/s004420050590

14. Walker, B.G., Boersma, P.D., \& Wingfield, J.C. 2005. Field endocrinology and conservation biology. Integr Comp Biol 45:12-18.

http://dx.doi.org/10.1093/icb/45.1.12

15. Arlettaz, R., Patthey, P., Baltic, M., Leu, T., Schaub, M., Palme, R., \& Jenni-Eiermann, S. 2007. Spreading free-riding snow sports represent a novel serious threat for wildlife. P Roy Soc B 274:1219-1224.

http://dx.doi.org/10.1098/rspb.2006.0434

16. Wasser, S.K., Hunt, K.E., Brown, J.L., Cooper, K., Crockett, C.M., Bechert, U., Millspaugh, J.J., Larson, S., \& Monfort, S.L. 2000. A generalized fecal glucocorticoid assay for use in a diverse array of non-domestic mammalian and avian species. Gen Comp Endocrinol 120:260-275. http://dx.doi.org/10.1006/gcen.2000.7557

17. • Millspaugh, J.J., \& Washburn, B.E. 2004. Use of fecal glucocorticoid metabolite measures in conservation biology research: considerations for application and interpretation. Gen Comp Endocr 138:189-199.

http://dx.doi.org/10.1016/j.ygcen.2004.07.002 
18. Smith, J.E., Monclús, R., Wantuck, D., Florant, G.L. \& Blumstein, D.T. 2012. Fecal glucocorticoid metabolites in wild yellow-bellied marmots: Experimental validation, individual differences and ecological correlates. Gen Comp Endocr 178:417-426. http://dx.doi.org/10.1016/j.ygcen.2012.06.015

19. Narayan, E.J., Webster, K., Nicolson, V., Mucci, A. \& Hero, J.M. 2013. Non-invasive evaluation of physiological stress in an iconic Australian marsupial: the koala (Phascolarctos cinereus). Gen Comp Endocr 187: 39-47. http://dx.doi.org/10.1016/j.ygcen.2013.03.021

20. Sheriff, M.J., Krebs, C.J., \& Boonstra, R. 2010. Assessing stress in animal populations: Do fecal and plasma glucocorticoids tell the same story? Gen Comp Endocr 166:614-619. http://dx.doi.org/10.1016/j.ygcen.2009.12.017

21. Sheriff, M.J., Dantzer, B., Delehanty, B., Palme, R. \& Boonstra, R. 2011. Measuring stress in wildlife: techniques for quantifying glucocorticoids. Oecologia 166: 869-887. http://dx.doi.org/10.1007/s00442-011-1943-y

22. Harper, J.M., \& Austad, S.N. 2000. Fecal glucocorticoids: a noninvasive method of measuring adrenal activity in wild and captive rodents. Physiol Biochem Zool 73:12-22. http://dx.doi.org/10.1086/316721

23. Le Maho, Y., Karmann, H., Briot, D., Handrich, Y., Robin, J.P., Mioskowski, E., Cherel, Y., \& Farni, J. 1992. Stress in birds due to routine handling and a technique to avoid it. Am J Physiol 263:R775-R781.

24. Romero, L.M., \& Reed, J.M. 2005. Collecting baseline corticosterone samples in the field: is under 3 min good enough? Comp Biochem Physiol A 140:73-79.

http://dx.doi.org/10.1016/j.cbpb.2004.11.004

Seudkamp Wells, K.M., Washburn, B.E., Millspaugh, J.J., Ryan, M.R., \& Hubbard, M.W. 2003. Effects of radio-transmitters on fecal glucocorticoid levels in captive dickcissels. Condor 105:805-810.

http://dx.doi.org/10.1650/7174

26. Pereira, R.J.G., Granzinolli, M.A.M., Barros, F.M., \& Duarte, J.M.B. 2009. Influence of radiotransmitters on fecal glucocorticoid levels of free-ranging male American kestrels. J Wildlife Manage 73:772-778. http://dx.doi.org/10.2193/2008-184

Washburn BE, Millspaugh JJ, Schulz JH, Jones SB, Mong T. 2003. Using fecal glucocorticoids for stress assessment in mourning doves. Condor 105: 696-706. http://dx.doi.org/10.1650/7216

28. Reeves, H.M., Geis, A.D., \& Kniffin, F.C. 1968. Mourning dove capture and banding. Special Scientific Report-Wildlife 117, U.S. Fish and Wildlife Service, Washington, D.C.

29. Mirarchi, R.E. 1993. Sexing, aging, and miscellaneous research techniques. In: Baskett,T.S., Sayre, M.W., Tomlinson, R.E. \& Mirarchi, R.E. (eds.). Ecology and management of the mourning dove. Wildlife Management Institute, Washington, D.C., pp 399-408.

30. Schulz, J.H., Sheriff, S.L., He, Z., Braun, C.E., Drobney, R.D., Tomlinson, R.E., Dolton, D.D., \& Montgomery, R.A. 1995. Accuracy of techniques used to assign mourning dove age and gender. J Wildl Manage 59:759-765.

http://dx.doi.org/10.2307/3801953

31. Mong, T.W., Schulz, J.H., \& Millspaugh, J.J. 2002. Design and construction of mourning dove research pens. T Missouri Acad Sci 36:21-24.

32. Breuner, C.W., Wingfield, J.C. \& Romero, L.M. 1999. Diel rhythms of basal and stress-induced corticosterone in a wild, seasonal vertebrate, Gambel's white-crowned sparrow. J Exp Zool 284:334-342. 
33. Tarlow, E.M., Hau, M., Anderson, D.J., \& Wikelski, M. 2003. Diel changes in plasma melatonin and corticosterone concentrations in tropical Nazca boobies (Sula granti) in relation to moon phase and age. Gen Comp Endocr 133: 297-304.

http://dx.doi.org/10.1016/S0016-6480(03)00192-8

34. Schwarzenberger, F., Möstl, E., Bamberg, E., Pammer, J. \& Schmehlik, O. 1991. Concentrations of progestagens and oestrogens in the faeces of pregnant lipizzan, trotter and thoroughbred mares. J Reprod Fertil Suppl 44:489-499.

35. Brown, J.L., Bellem, A.C., Fouraker, M., Wildt, D.E., \& Roth, T.L. 2001. Comparative analysis of gonadal and adrenal activity in the black and white rhinoceros in North America by noninvasive endocrine monitoring. Zoo Biol 20:463-486.

http://dx.doi.org/10.1002/zoo.10028

36. Roy, C., \& Woolf, A. 2001. Effects of hunting and hunting-hour extension on Mourning Dove foraging and physiology. J Wildl Manage 65:808-815.

http://dx.doi.org/10.2307/3803030

37. Washburn, B.E., Morris, D.L., Millspaugh, J.J., Faaborg, J. \& Schulz, J.H. 2002. Using a commercially available radioimmunoassay to quantify corticosterone in avian plasma. Condor 104:558-563.

http://dx.doi.org/10.1650/0010-5422(2002)104[0558:UACART]2.0.CO;2

38. Otis, D.L. \& White, G.C. 2002. Re-analysis of a banding study to test the effects of an experimental increase in bag limits of mourning doves. J App Stat 29:479-495.

http://dx.doi.org/10.1080/02664760120108539

39. Otis, D.L. 2006. Mourning dove hunting regulation strategy based on annual harvest statistics and banding data. J Wildl Manage 70:1302-1307.

http://dx.doi.org/10.2193/0022-541X(2006)70[1302:MDHRSB]2.0.CO;2

40. Otis, D.L., Schulz, J.H. \& Scott, D.P. 2008. Mourning dove (Zenaida macroura) harvest and population parameters derived from a national banding study. U.S. Department of Interior, Fish and Wildlife Service, Biological Technical Publication FWS/BTP-R3010-2008, Washington, DC, USA.

41. Romero, L.M. \& Wingfield, J.C. 1999. Alterations in hypothalamic-pituitary-adrenal function associated with captivity in Gambel's white-crowned sparrows (Zonotrichia leucophrys gambelii). Comp Biochem Physiol 122B:13-20.

http://dx.doi.org/10.1016/S0305-0491(98)10161-X

42. Marra, P.P., Lampe, K.T., \& Tedford, B.L. 1995. Plasma corticosterone levels in two species of Zonotrichia sparrows under captive and free-ranging conditions. Wilson Bull 107:296-305.

43. Romero, L.M. 2004. Physiological stress in ecology: lessons from biomedical research. Trends Ecol Evol 19:249-255.

http://dx.doi.org/10.1016/j.tree.2004.03.008

44. Cyr, N.E., \& Romero, L.M. 2007. Chronic stress in free-living European starlings reduces corticosterone concentrations and reproductive success. Gen Comp Endocr 151:82-89.

http://dx.doi.org/10.1016/j.ygcen.2006.12.003

45. Dickens, M.J., Earle, K.A., \& Romero, L.M. 2009. Initial transference of wild birds to captivity alters stress physiology. Gen Comp Endocr 160:76-83.

http://dx.doi.org/10.1016/j.ygcen.2008.10.023

46. Romero, L.M., Soma, K.K. \& Wingfield, J.C. 1998a. Changes in pituitary and adrenal sensitivities allow the Snow Bunting (Plectrophenax nivalis), an Arctic-breeding songbird, to modulate corticosterone release seasonally. J Comp Physiol B 168:353-358.

http://dx.doi.org/10.1007/s003600050154 
47. Romero, L.M., Soma, K.K. \& Wingfield, J.C. 1998b. The hypothalamus and adrenal regulate modulation of coricosterone release in redpolls (Carduelis flammea - an Arctic-breeding song bird). Gen Comp Endocr 109:347-355.

http://dx.doi.org/10.1006/gcen.1997.7048

48. Romero, L.M., \& Remage-Healey, L. 2000. Daily and seasonal variation in response to stress in captive Starlings (Sturnus vulgaris): corticosterone. Gen Comp Endocr 119:52-59. http://dx.doi.org/10.1006/gcen.2000.7491

49. Romero, L.M. 2002. Seasonal changes in plasma glucocorticoid concentrations in free-living vertebrates. Gen Comp Endocr 128:1-24.

http://dx.doi.org/10.1016/S0016-6480(02)00064-3

50. Landys, M.M., Goymann, W., Schwabl, I., Trapschuh, M., \& Slagsvold, T. 2010. Impact of season and social challenge on testosterone and corticosterone levels in a year-round territorial bird. Horm Behav 58: 317-325.

http://dx.doi.org/10.1016/j.yhbeh.2010.02.013

51. Romero, L.M., Ramenofsky, M., \& Wingfield, J.C. 1997. Season and migration alters the corticosterone response to capture and handling in an Arctic migrant, the White-crowned sparrow (Zonotrichia leucophrys gambelii). Comp Biochem Physiol 116C:171-177.

52. Jachowski, D.S., Slotow, R., \& Millspaugh, J.J. 2013. Delayed physiological acclimatization by African elephants following reintroduction. Anim Conserv 16:575-583. http://dx.doi.org/10.1111/acv.12031

53. Ninnes, C.E., Waas, J.R., Ling, N., Nakagawa, S., Banks, J.C., Bell, D.G., Bright, A., Carey, P.W., Chandler, J., Hudson, Q.J., et al. 2010. Comparing plasma and faecal measures of steroid hormones in Adelie penguins Pygoscelis adeliae. J Comp Phys B 180: 83-94. http://dx.doi.org/10.1007/s00360-009-0390-0

54. Ellenberg, U., Setiawan, A.N., Cree, A., Houston, D.M., \& Seddon, P.J. 2007. Elevated hormonal stress response and reduced reproductive output in yellow-eyed penguins exposed to unregulated tourism. Gen Comp Endocr 152: 54-63.

http://dx.doi.org/10.1016/j.ygcen.2007.02.022

55. Cry, N.E., \& Romero, L.M. 2008. Fecal glucocorticoid metabolites of experimentally stressed captive and free-living starlings: Implications for conservation research. Gen Comp Endocr 158:20-28.

http://dx.doi.org/10.1016/j.ygcen.2008.05.001 